\title{
Significance of abnormal echoes in left ventricular outflow tract
}

\author{
P. A. N. CHANDRARATNA, M. J. ROBINSON, C. BYRD, \\ AND J. V. PITHA \\ With the technical assistance of Dale Gindlesperger and Paula Arabie \\ From the Division of Cardiology, Department of Medicine, and Department of Pathology, \\ University of Oklahoma Health Sciences Center, Oklahoma City, Oklahoma; and the \\ Division of Cardiology, Department of Medicine, and Department of Surgery, Mount Sinai \\ Medical Center, Miami, Florida, U.S.A.
}

We have observed abnormal echoes in the left ventricular outflow tract in 4 patients: 3 of the subjects had bacterial endocarditis and the fourth patient had myxomatous degeneration of the aortic valve (floppy aortic valve). A single diastolic echo with fine high frequency fluttering was seen in the patient with the floppy aortic valve, whereas the patients with endocarditis had dense diastolic echoes. One of the subjects with endocarditis had associated infection of the mitral valve and an aneurysm of the anterior mitral leaflet, which was represented by dense systolic echoes on the proximal part of the mitral valve. Bacteriological cure in one of our patients resulted in the disappearance of the abnormal echoes on the aortic valve and the left ventricular outflow tract. No aortic valve destruction or abnormality was observed in a subject with endocarditis and severe aortic regurgitation; aortic regurgitation in this patient may have resulted from the presence of vegetations preventing valve closure.

The left ventricular outflow tract is represented on an $M$-mode echocardiogram by an echo-free space between the upper part of the interventricular septum and the anterior mitral leaflet. In normal subjects, its width is 20 to $34 \mathrm{~mm}$ (Gramiak and Waag, 1975). Narrowing of the left ventricular outflow tract occurs in idiopathic hypertrophic subaortic stenosis and in discrete membranous subaortic stenosis (Shah et al., 1969; Popp et al., 1974). The presence of echoes in the left ventricular outflow tract is an abnormal phenomenon. This report describes abnormal echoes in the outflow tract of the left ventricle in 3 patients with bacterial endocarditis and in a patient who had myxomatous degeneration of the aortic valve with aortic valve prolapse. One of the patients with bacterial endocarditis also had an aneurysm of the anterior mitral leaflet which produced an unusual echocardiographic picture.

\section{Subjects and methods}

Four patients with severe aortic regurgitation were noted to have abnormal echoes in the left ventricular Received for publication 23 August 1976 outflow tract on their echocardiograms. Three patients had bacterial endocarditis and the fourth patient had myxomatous degeneration of the aortic valve. The relevant clinical data are summarised in the Table.

The first patient had vegetations on a structurally normal valve. There were no perforations or tears of the aortic valve cusps at operation. The second patient had aortic valve replacement three months after bacteriological cure of subacute bacterial endocarditis. At operation, an acutely inflamed, oedematous bicuspid aortic valve was seen; there was no aortic valve calcification. The third patient died in spite of antibiotic therapy for endocarditis. At necrospy, the aortic valve was tricuspid and was not calcified; there were vegetations on all three

Table Clinical data

\begin{tabular}{lllll}
\hline $\begin{array}{l}\text { Case } \\
\text { No. }\end{array}$ & Age & Sex & Infecting organism & Clinical course \\
\hline 1 & 24 & M & $\begin{array}{l}\text { Haemolytic } \\
\text { streptococcus }\end{array}$ & Successful operation \\
2 & 31 & M & $\begin{array}{l}\text { Streptococcus viridans } \\
\text { Group D streptococcus }\end{array}$ & $\begin{array}{l}\text { Successful operation } \\
\text { Died } \\
\text { Successful operation }\end{array}$ \\
\hline & 65 & M & - & F
\end{tabular}



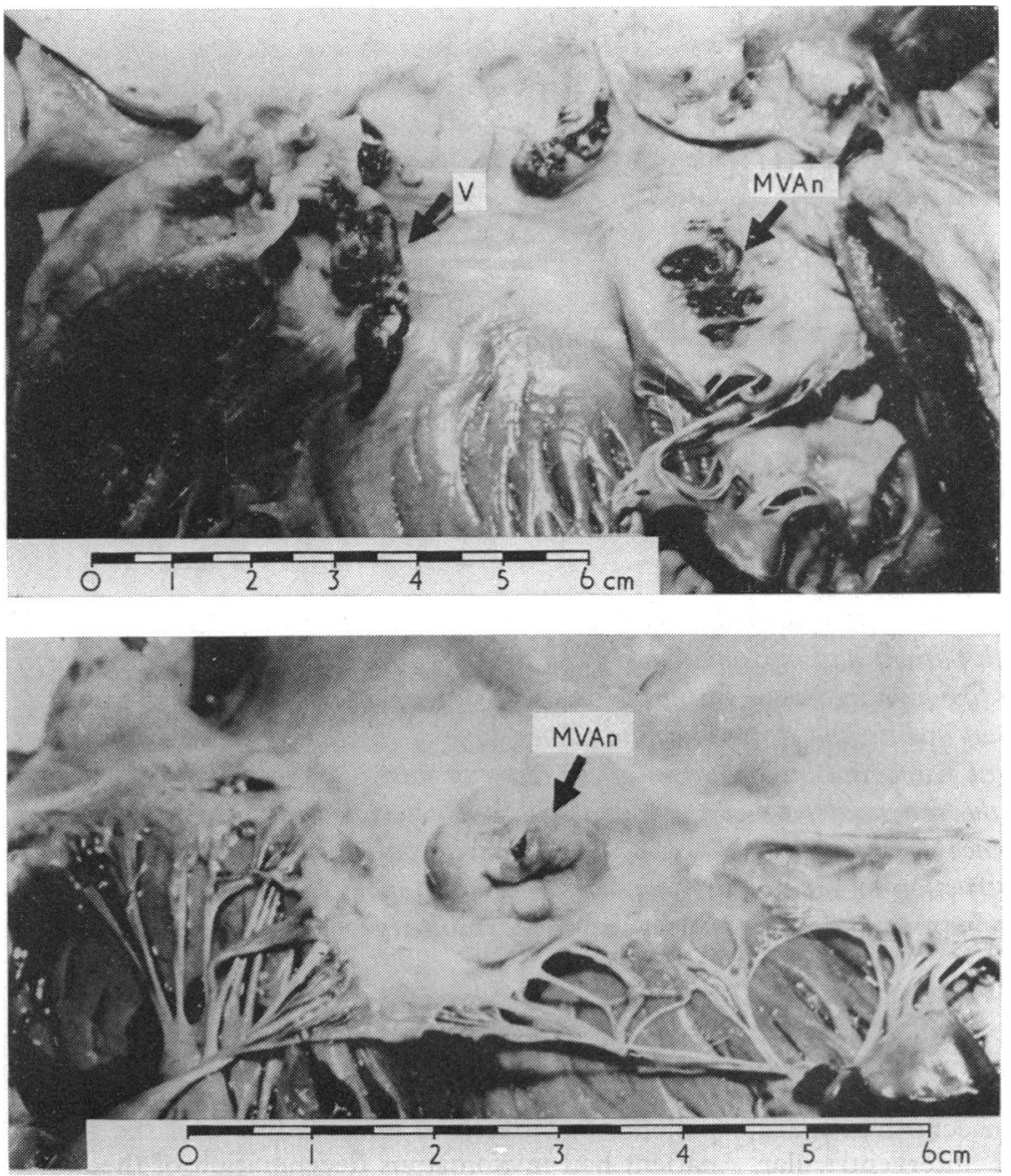

Fig. 1 Case 3. Vegetations are seen on the aortic valve. $A$ long vegetation $(V)$ lies in the left ventricular outflow tract. $A$ mitral valve aneurysm (MVAn) has formed at the site of vegetation on the anterior mitral leaflet.

Fig. 2 Case 3. Anterior mitral leaflet showing the mitral valve aneurysm (MVAn) from the atrial surface. $A$ small perforation is seen at the centre of the aneurysm. cusps (Fig. 1). A perforation of the left coronary cusp was noted and the right coronary cusp had a large vegetation which protruded into the left ventricular outflow tract. Large vegetations were found on the ventricular surface of the anterior mitral leaflet and an aneurysm with a small perforation was noted on its atrial surface (Fig. 2), this corresponded to the site of attachment of the vegetations. Histological examination of the valve at the site of the aneurysm showed inflammatory changes which suggested that this had resulted from endocarditis. The fourth patient presented with severe aortic regurgitation and obvious limitation of exercise tolerance. At operation, a redundant, floppy aortic valve which prolapsed into the left ventricular outflow tract was noted. Histological examination of the valve showed myxomatous degeneration (Fig. 3).

The patients were supine during the echocardiographic examination. An Ekoline 20 ultrasonoscope, a $10 \mathrm{~cm}$ focus, $0.5^{\prime \prime}, 2.25 \mathrm{MHz}$ transducer, and a strip chart recorder were used. An M-mode scan from the aortic root to the left ventricle was performed on each patient.

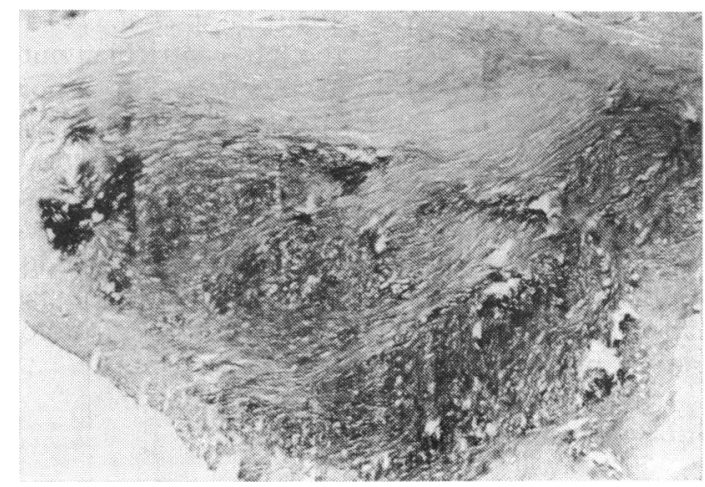

Fig. 3 Case 4. Photomicrograph of the aortic valve. The section has been stained with Alcian blue and the dark areas represent myxomatous degeneration. 


\section{Results}

The echocardiogram of Case 1 is shown in Fig. 4. The aortic valve has a normal appearance in systole with good motion of the right and non-coronary cusp. Thick echoes are seen in diastole, which probably represent vegetations on the valve. An abnormal echo $(\mathrm{V})$ is seen between the anterior mitral leaflet and the interventricular septum, i.e. in the proximal part of the left ventricular outflow tract. In the normal subject, no echoes are seen in the left ventricular outflow tract (Fig. 5). The left ventricle was enlarged and the motion of its walls was exaggerated. Fine fluttering of the anterior mitral leaflet was present.

The first echocardiogram of Case 2 (Fig. 6) was recorded during his first hospital admission, when he had physical signs of bacterial endocarditis and positive blood cultures. Abnormal thick echoes are seen in the region of the aortic valve in diastole and are probably caused by vegetations on the valve. Abnormal diastolic echoes are also present in the left ventricular outflow tract. The echocardiogram taken three months after bacteriological cure of the endocarditis is shown in Fig. 7. The abnormal echoes which were present on the aortic valve cusps and in the left ventricular outflow tract are no longer seen. The aortic valve is eccentric in diastole suggesting that the valve is bicuspid (Nanda et al., 1974; Radford et al., 1976).

The M-mode scan of Case 3 is depicted in Fig. 8. In systole the aortic valve cusps appear normal, whereas in diastole dense echoes are seen to fill most of the aortic root. A thick mass of echoes is also seen in the left ventricular outflow tract. Near the base of the mitral valve there are dense echoes within the substance of the valve (posterior to the echo from the vegetation) in diastole and systole

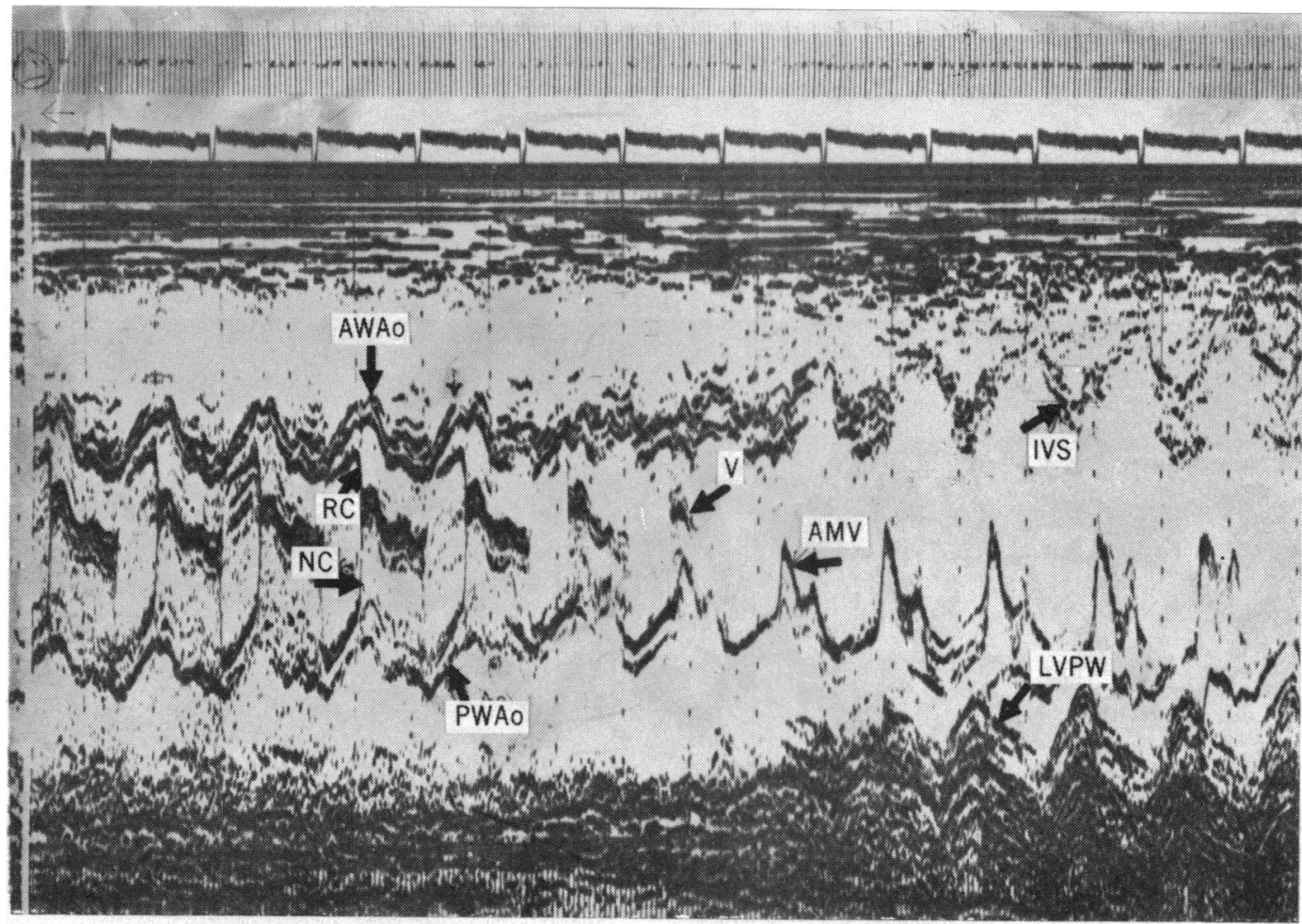

Fig. 4 Case 1. Echocardiogram showing good motion of the aortic valve leaflets and dense echoes on the aortic valve in diastole representing vegetations. Note an echo $(V)$ in the left ventricular outflow tract, i.e. between the anterior mitral leaflet $(A M V)$ and the proximal part of the interventricular septum (IVS). RC, right coronary cusp; NC, noncoronary cusp; $A W A$ o, anterior wall of aortic root; $P W A o$, posterior wall of aortic root; $L V P W$, posterior wall of left ventricle. 


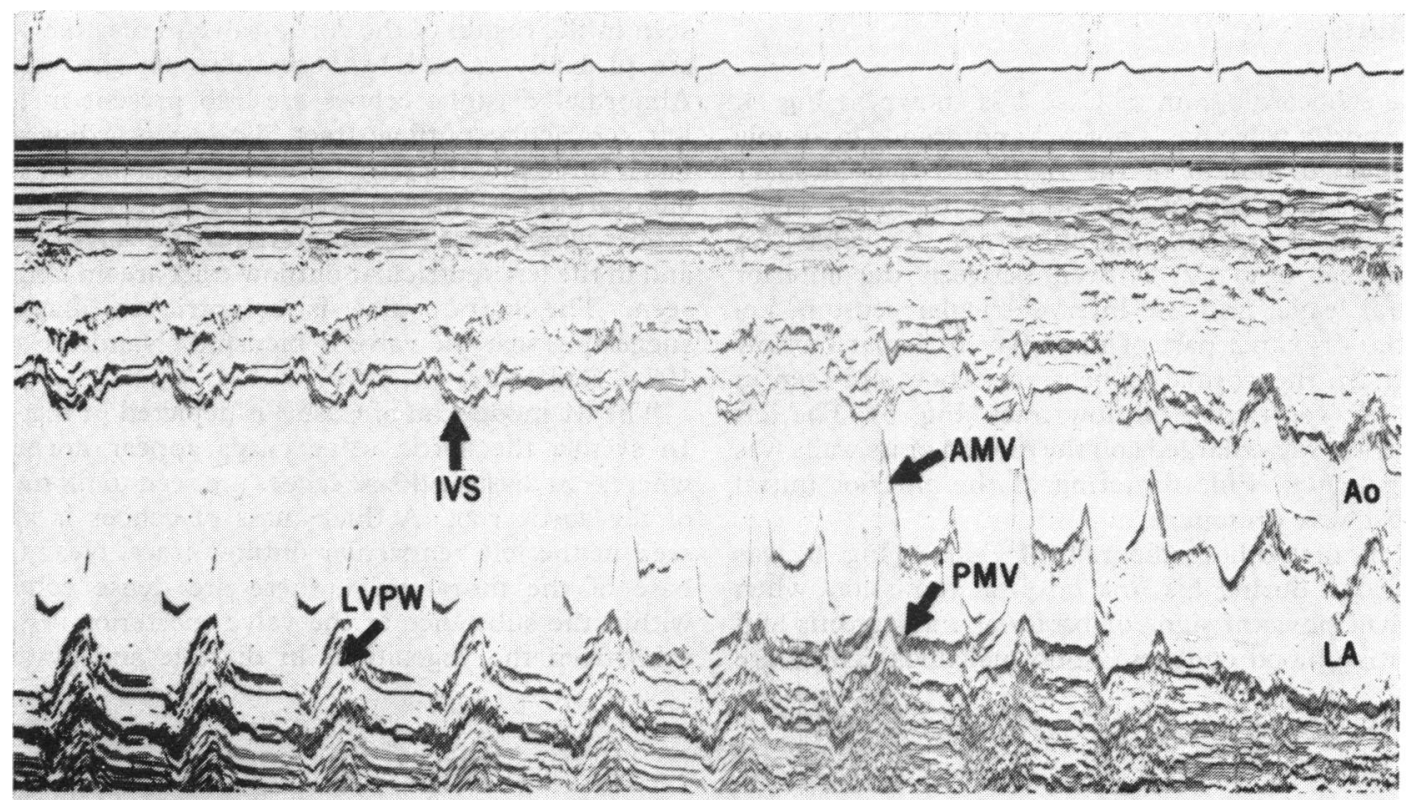

Fig. 5 Echocardiogram from a normal athlete showing a sweep from the left ventricle to the aortic root (Ao). Note that there are no echoes between the anterior mitral leaflet $(A M V)$ and the interventricular septum (IVS). $L V P W$, posterior wall left ventricle; $L A$, left atrium.

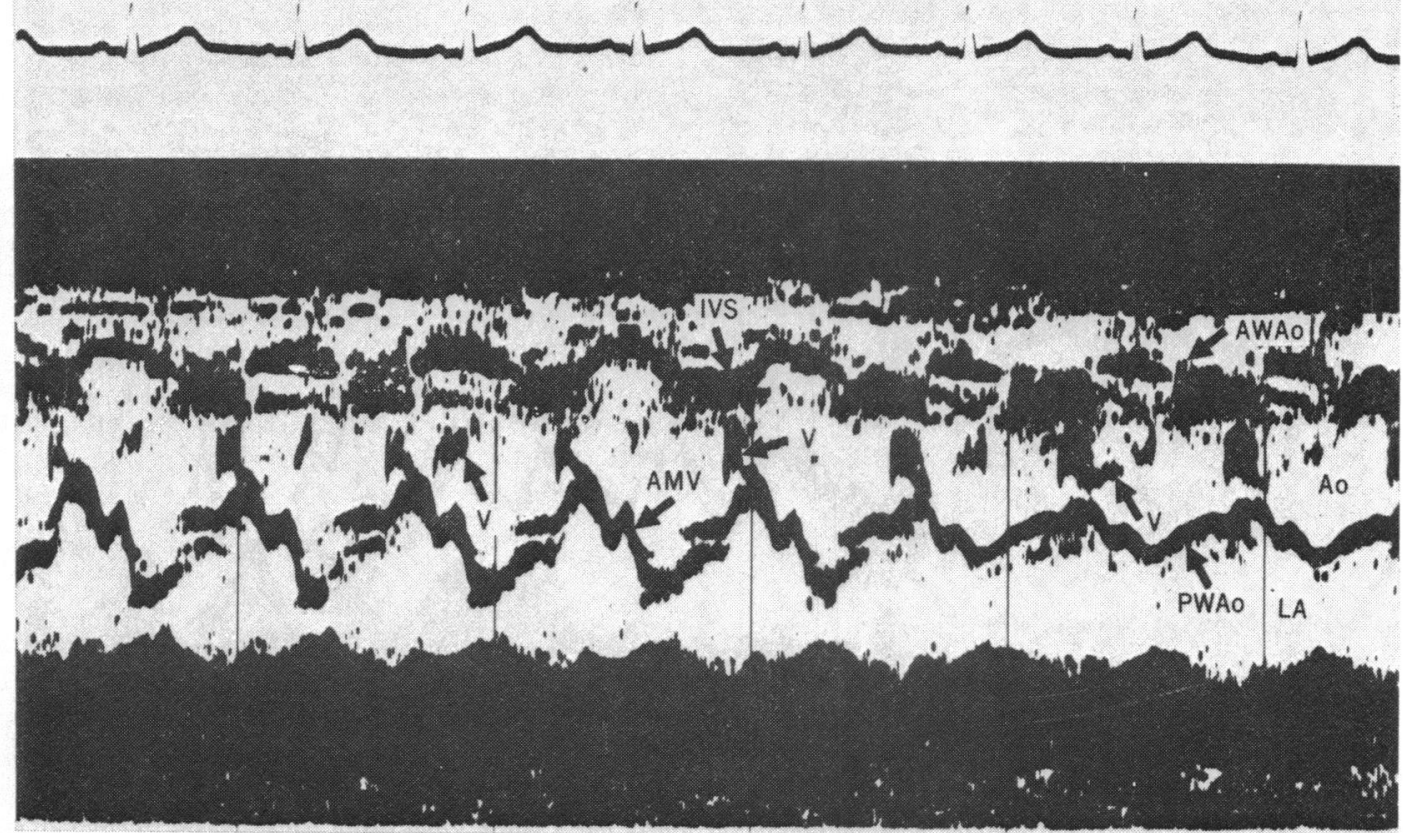

Fig. 6 Case 2. Echocardiogram before treatment showing dense echoes in diastole in the region of the aortic valve, which probably represent vegetations $(V)$. Similar diastolic echoes are seen in the left ventricular outflow tract, i.e. between the anterior mitral leaflet $(A M V)$ and the interventricular septum (IVS). AW Ao, anterior wall of aortic root; $P W A o$, posterior wall of aortic root; Ao, aortic root; $L A$, left atrium. 
(Fig. 9). The tip of the valve, however, shows thin linear echoes from the anterior and posterior mitral leaflets. Fluttering of the anterior mitral leaflet was present and the left ventricle was enlarged with exaggerated motion of its walls.

The M-mode scan on Case 4 (Fig. 10) shows an abnormal echo in the left ventricular outflow tract in early diastole. The aortic valve in this patient shows fine high frequency fluttering in diastole (Fig. 11). There was also fine fluttering of the anterior mitral leaflet, and an enlarged left ventricle with good wall motion.

\section{Discussion}

Dense echoes on the aortic valve in diastole suggested the diagnosis of endocarditis in our patients. The echocardiographic features of bacterial endocarditis were first described by Dillon and associates (1973) and subsequently confirmed by others
(Hirschfeld and Schiller, 1974; Gottlieb et al., 1974; Martinez et al., 1974; De Maria et al., 1975; Gramiak and Waag, 1975).

Abnormal echoes in the left ventricular outflow tract were present in all our 4 patients. Three patients had bacterial endocarditis. The fourth patient had a floppy aortic valve. In a recent review of the echocardiographic manifestations of bacterial endocarditis, Wray (1975b) observed that echoes in the left ventricular outflow tract were present in 1 case. Gramiak and Waag (1975) described another case, and Guiliani et al. (1975) described 8 cases of endocarditis with abnormal echoes in the left ventricular outflow tract. In one of our patients (Case 3 ), there was a large long vegetation hanging free in the left ventricular outflow tract at necropsy, thus confirming the echocardiographic interpretation.

The patient with aortic valve prolapse showed fine high frequency fluttering of the aortic valve in

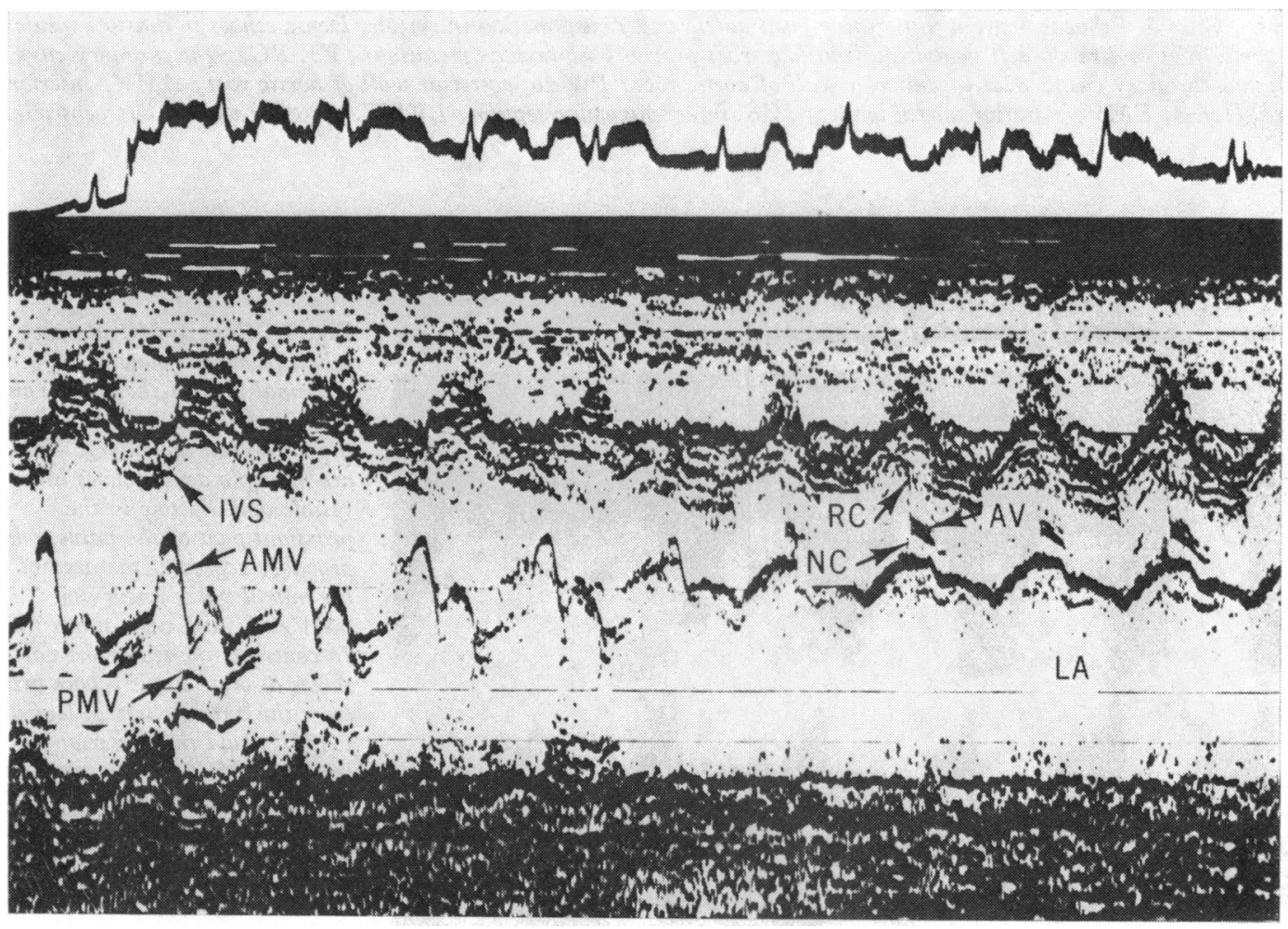

Fig. 7 Case 2. Echocardiogram after bacteriological cure of endocarditis. The eccentric position of the aortic valve in diastole suggests a bicuspid valve. The dense echoes seen inside the aortic root and the left ventricular outflow tract on the previous tracing are no longer present. $R C$, right coronary cusp; $N C$, non-coronary cusp; $A M V$, anterior mitral leaflet; PMV, posterior mitral leaflet; IVS. interventricular septum; $A V$, aortic valve; $L A$, left atrium. 


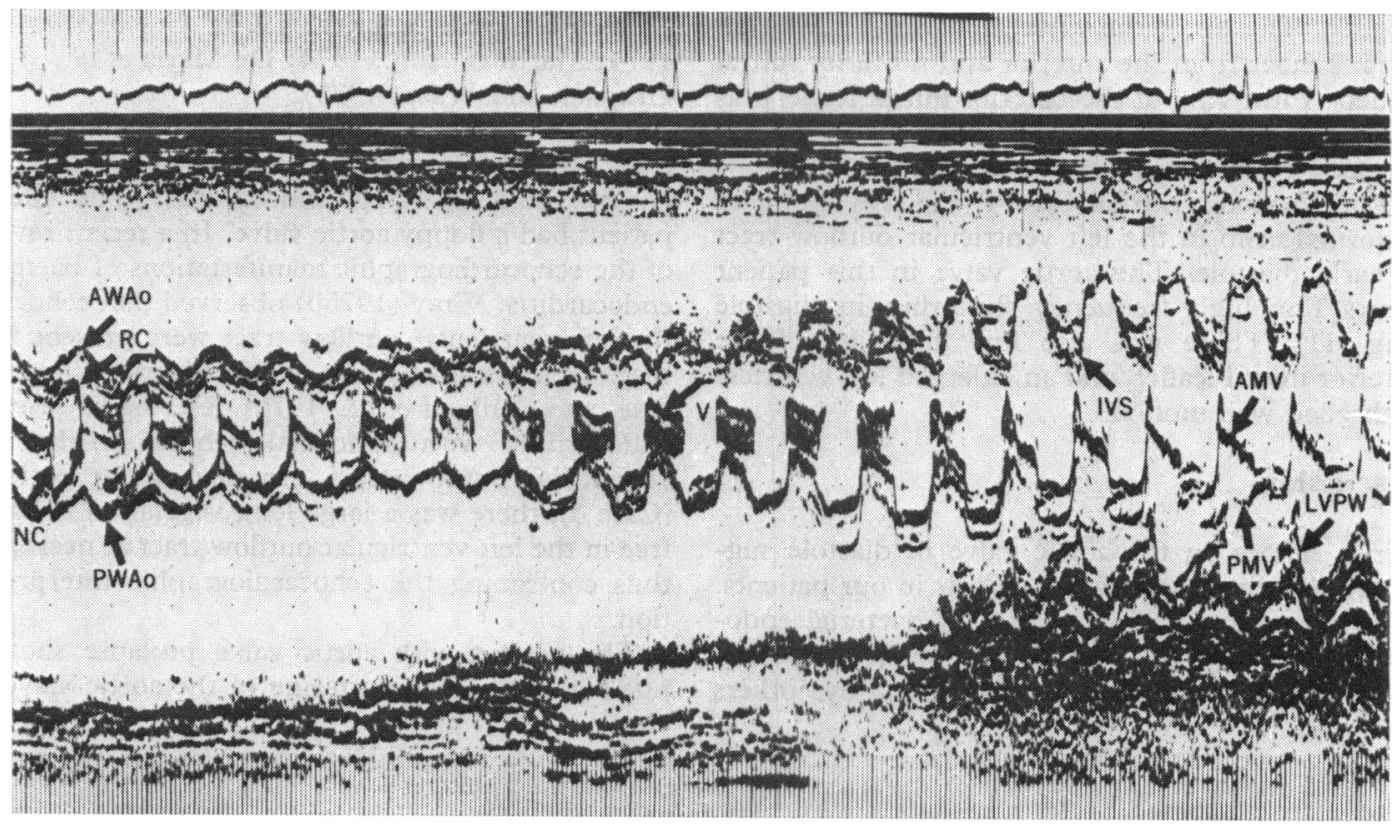

Fig. 8 Case 3. Echocardiogram illustrating good aortic valve cusp motion in systole. Dense echoes in diastole inside the aortic root and in the left ventricular outflow tract probably represent vegetations $(V)$. RC, right coronary cusp; $N C$, non-coronary cusp; $A W A$, anterior wall of aortic root; $P W A o$, posterior wall of aortic root; $A M V$, anterior mitral leaflet; PMV, posterior mitral leaflet; IVS, interventricular septum; LVPW, posterior wall of left ventricle.

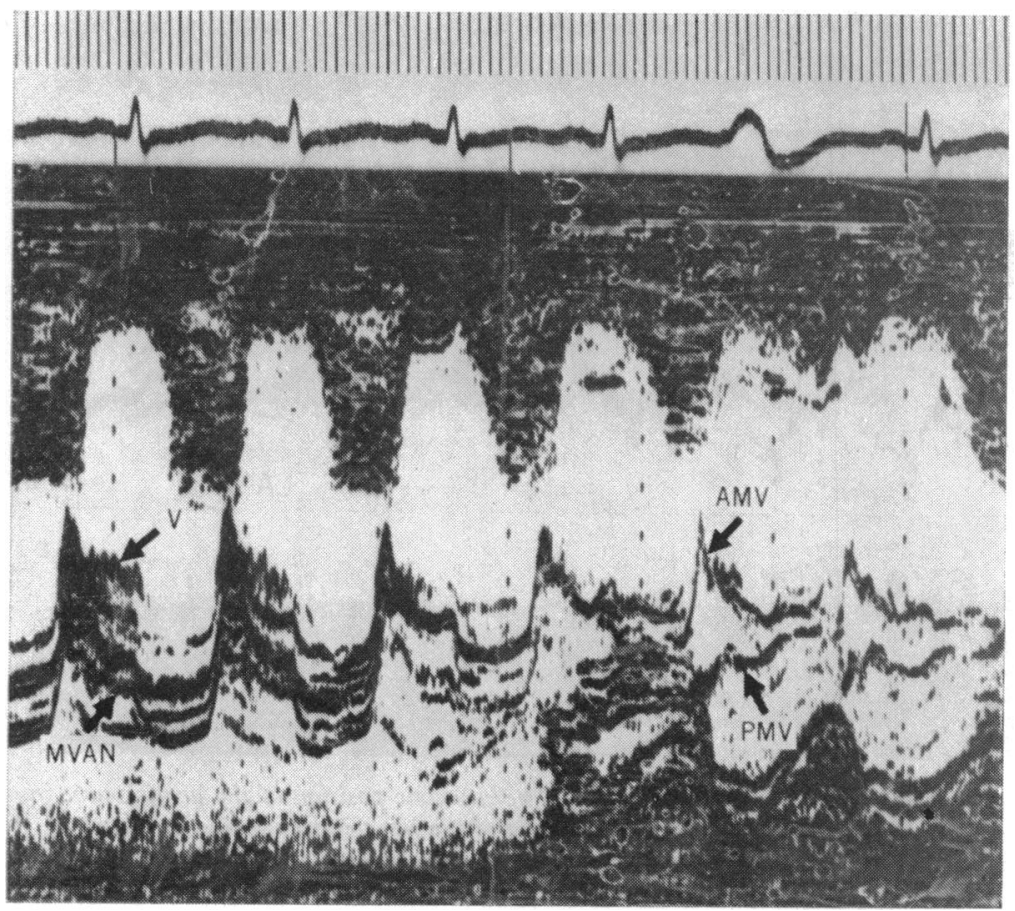

Fig. 9 Case 3. Mitral valve echocardiogram showing the proximal part of the valve (on the left of figure) and the tip of the valve (on the right). There are multiple dense echoes in systole and diastole in the proximal part of the valve, which probably represent the area of the mitral valve aneurysm (MVAN) and vegetations (V). In contrast, the tip of the valve shows discrete single echoes arising from the anterior mitral leaflet $(A M V)$ and the posterior leaflet (PMV). 


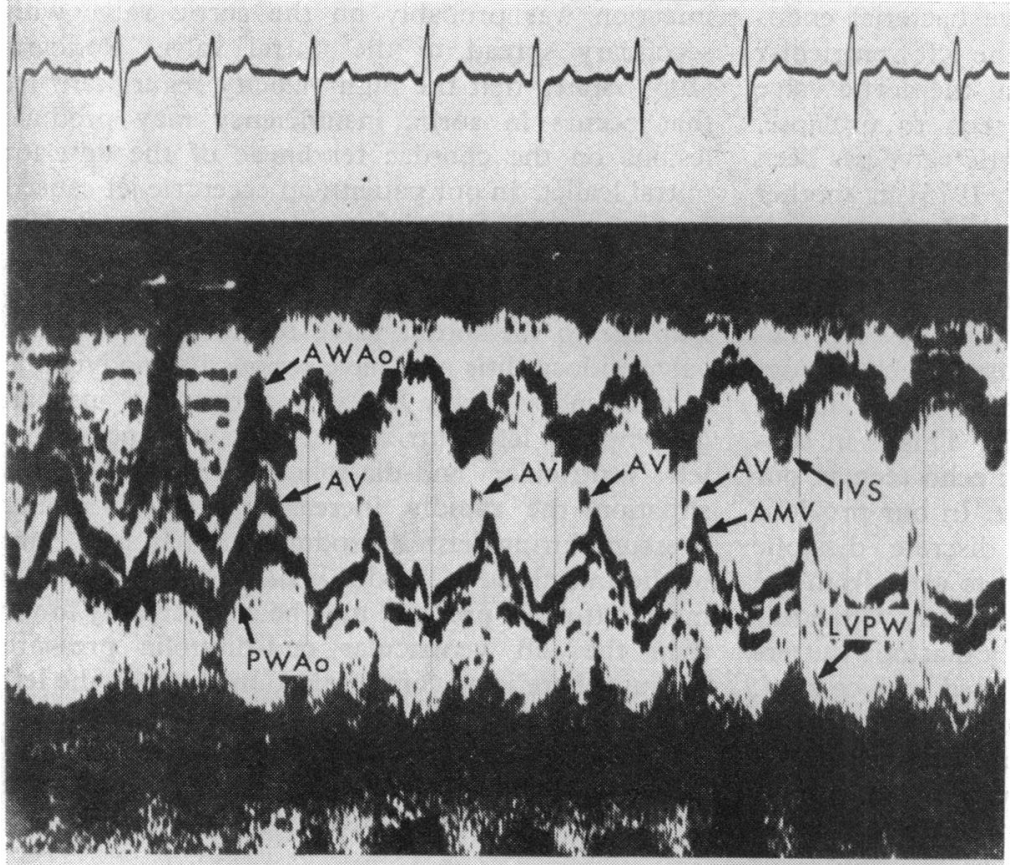

Fig. 10 Case 4. Echocardiogram showing scan from aortic root to left ventricle. Diastolic echoes are seen in the left ventricular outflow tract, and probably arise from the floppy aortic valve which was seen at operation. $A W A o$, anterior wall of aortic root; $P W A o$, posterior wall of aortic root; $A V$, aortic valve; $A M V$, anterior mitral leaflet; IVS, interventricular septum.

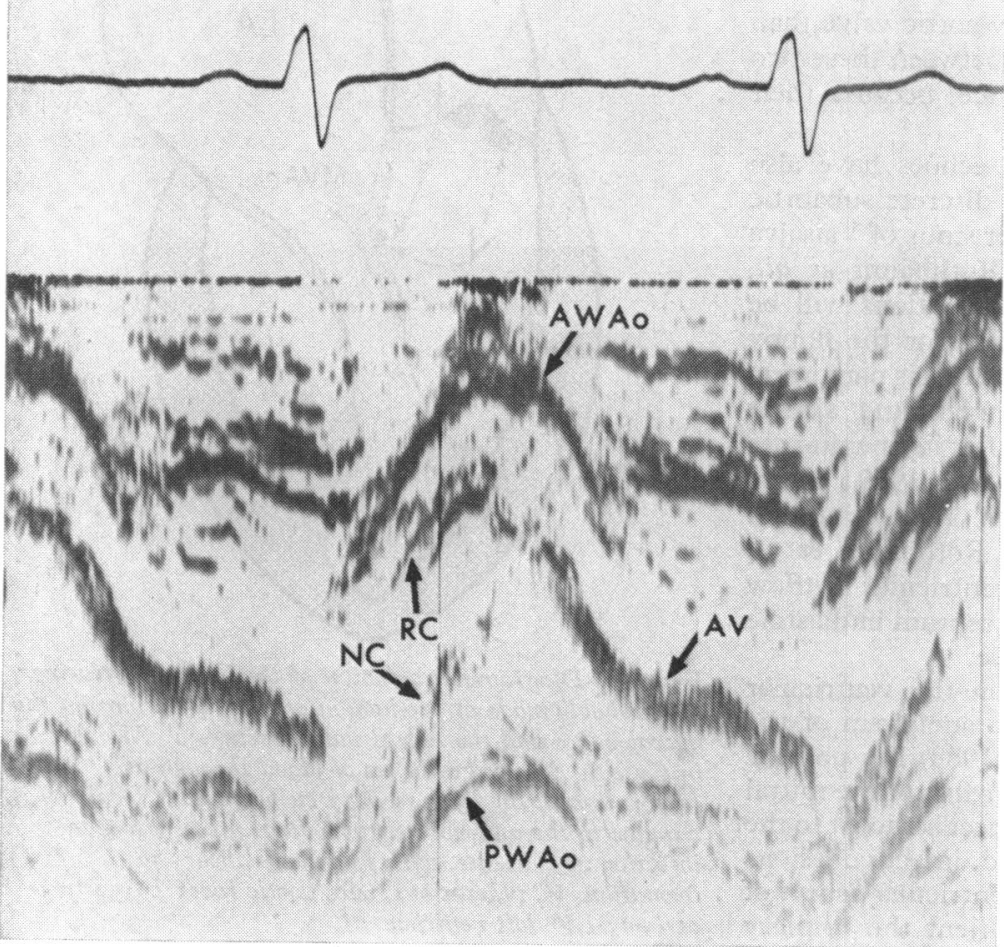

Fig. 11 Case 4. Echocardiogram of the aortic root shows fine high frequency diastolic fluttering of the aortic valve $(A V)$. RC, right coronary cusp; NC, noncoronary cusp; $A W A$, anterior wall of aortic root; $P W A$, posterior wall of aortic root. 
diastole. The patient did not have bacterial endocarditis. The abnormal echo in the left ventricular outflow tract probably arose from the aortic valve itself, which at operation was seen to prolapse. Fine diastolic fluttering of the aortic valve has been noted by us (Chandraratna et al., 1975) in another patient with a floppy aortic valve. Irregular high frequency diastolic fluttering was reported in a patient with destruction of an aortic valve leaflet as a result of bacterial endocarditis (Wray, 1975a), but in this patient multiple linear diastolic echoes suggestive of endocarditis had been observed on the aortic valve one month previously. This is in contrast to the single linear diastolic echo seen in our patient with aortic valve prolapse. In our previous patient with this entity, two discrete diastolic echoes were seen which appeared to arise from the right and non-coronary cusp, respectively (Chandraratna et al., 1975). High frequency diastolic fluttering of the aortic valve was also noted by Lee et al. (1974) in 4 patients with ruptured aortic valve leaflet; neither the aetiology of cusp rupture nor the presence of the left ventricular outflow tract echoes was mentioned in this communication. Thus, though the differential diagnosis of conditions causing abnormal echoes in the left ventricular outflow tract is difficult; the presence of a single echo or two discrete aortic valve echoes in diastole and fine high frequency diastolic fluttering of the valve are more in favour of floppy aortic valve than endocarditis. The differentiation between these two conditions is of clinical importance, because their medical management is different.

Left ventricular outflow tract echoes have also been described in a patient with discrete subaortic stenosis and in a subject with right sinus of Valsalva aneurysm (Popp et al., 1974; Rothbaum et al., 1974). It is unlikely that these conditions will be confused with infective endocarditis or the floppy aortic valve. In discrete subaortic stenosis narrowing of the left ventricular outflow tract, and abrupt closure of the aortic valve shortly after its opening are characteristic features (Popp et al., 1969; Davis et al., 1974). The patient with right sinus of Valsalva aneurysm reported by Rothbaum et al. (1974) had an echo in the left ventricular outflow tract which moved away from the septum in diastole and toward the septum in systole.

Case 3 also had vegetations on the ventricular aspect of the mitral valve and an aneurysm of the anterior mitral leaflet. Rodbard (1963) has pointed out that the vegetations in endocarditis of the mitral valve usually occur on its atrial aspect adjacent to the line of closure. On the other hand, infective lesions of the aortic valve occur on the ventricular aspect of the valve cusps. Thus, in this patient the primary infection was probably on the aortic valve with secondary spread to the mitral valve. Rodbard (1963) states that the high velocity regurgitant jet that occurs in aortic insufficiency may produce lesions on the chordae tendineae of the anterior mitral leaflet. In our patient, an eccentric jet caused by perforation of the left coronary cusp resulted in infective endocarditis of the anterior mitral leaflet with secondary aneurysm formation (Fig. 12). Damage to the mitral valve resulting from aortic valve endocarditis may have serious haemodynamic consequences. Acute aortic regurgitation into an uncompliant left ventricle causes a sharp increase in left ventricular end-diastolic pressure. In this situation the rapidly increasing left ventricular pressure during diastole produces premature closure of the mitral valve (Pridie et al., 1971). Thus, the mean left atrial pressure may be considerably lower than the left ventricular end-diastolic pressure because there is no communication between the left atrium and the left ventricle during the latter part of diastole. However, if there were a perforation of the anterior mitral leaflet or rupture of the chordae

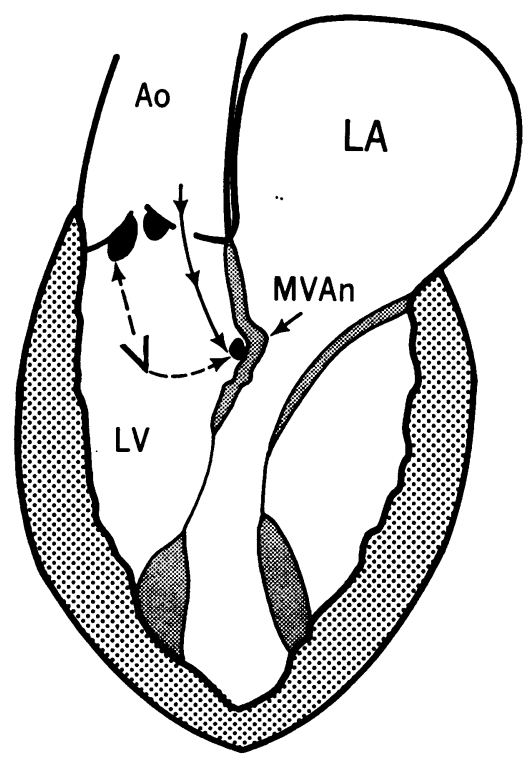

Fig. 12 Diagrammatic section of the heart illustrating the probable mode of production of the vegetations on the mitral valve and the mitral valve aneurysm (MVAn) in Case 3. A regurgitant jet of blood through a perforation in the left coronary cusp produces local damage to the anterior mitral leaflet, predisposing to infection at that site, with secondary aneurysm formation. $V$, vegetations; Ao, aortic root; $L A$, left atrium; $L V$, left ventricle. 
tendineae, the left ventricular end-diastolic pressure would be transmitted to the left atrium and severe pulmonary oedema might occur. The recognition of anterior mitral leaflet involvement in patients with aortic valve endocarditis is, therefore, of considerable clinical importance. The proximal part of the valve in our patient showed dense echoes in systole and diastole whereas the distal portion was normal. The dense echoes probably arose from the vegetations and from the aneurysm of the anterior mitral leaflet. We recommend serial echocardiographic examinations of the anterior mitral leaflet in patients with aortic valve endocarditis with a view to detection of mitral valve involvement.

It is of interest that Case 1 had severe aortic regurgitation without evidence of destruction or other abnormality of the valve at operation. The large vegetations on the aortic valve of this patient probably prevented proper valve closure with resulting aortic regurgitation. We have seen a similar patient, with large non-bacterial verrucous lesions on the aortic valve (marantic endocarditis) associated with carcinoma of the pancreas, who had severe aortic reflux with a structurally normal aortic valve at necropsy. It is conceivable that in some patients with aortic valve endocarditis without valve destruction, the degree of aortic regurgitation may decrease when bacteriological cure is achieved. Interference with valve closure by vegetations may be one of the mechanisms whereby a murmur increases or decreases in intensity during the course of infective endocarditis.

Case 2 had clear-cut clinical and bacteriological evidence of bacterial endocarditis. His echocardiogram showed abnormal echoes on the aortic valve and in the left ventricular outflow tract. The record taken after bacteriological cure showed complete disappearance of these echoes, suggesting that the vegetations were no longer present. The features suggestive of a bicuspid aortic valve (eccentric position of the aortic valve in diastole) which were noted on the echocardiogram after treatment were masked by the vegetations present on the initial echocardiogram. Thus, echocardiography is helpful in the diagnosis and follow-up of the patient with endocarditis.

\section{References}

Chandraratna, P. A. N., Samet, P., Robinson, M. J., and Byrd, C. (1975). Echocardiography of the floppy aortic valve. Circulation, 52, 959-962.

Davis, R. H., Feigenbaum, H., Chang, S., Konecke, L. L., and Dillon, J. C. (1974). Echocardiographic manifestations of discrete subaortic stenosis. American fournal of Cardio$\log y, 33,277-280$.

De Maria, A. N., King, J. F., Salel, A. F., Caudill, C. C., Miller, R. R., and Mason, D. T. (1975). Echography and phonography of acute aortic regurgitation in bacterial endocarditis. Annals of Internal Medicine, 82, 329-335.

Dillon, J. C., Feigenbaum, H., Konecke, K. L., Davis, R. H., and Chang, S. (1973). Echocardiographic manifestations of valvular vegetations. American Heart fournal, 86, 698-704.

Gottlieb, S., Khuddus, S. A., Balooki, H., Dominguez, A. E., and Myerburg, R. J. (1974). Echocardiographic diagnosis of aortic valve vegetations in candida endocarditis. Circulation, 50, 826-830.

Gramiak, R., and Waag, R. C. (1975). Cardiac Ultrasound. C. V. Mosby, Saint Louis.

Guiliani, E. R., Roy, P., Tajik, A. J., Gau, G. T., Schattenberg, T. T., and Frye, R. L. (1975). Abnormal echo in the left ventricular outflow tract in bacterial endocarditis (abstract). Circulation, 52, 11-69.

Hirschfeld, D., and Schiller, N. B. (1974). Echocardiographic localization of aortic valve vegetations (abstract). Circulation, 50, 111-143.

Lee, C. C., Das, G., and Weissler, A. M. (1974). Characteristic echocardiographic manifestations in ruptured aortic valve leaflet (abstract). Circulation, 50, 111-144.

Martinez, E. C., Burch, G. E., and Giles, T. D. (1974). Echocardiographic diagnosis of vegetative aortic bacterial endocarditis. American fournal of Cardiology, 34, 845-849.

Nanda, N. C., Gramiak, R., Manning, J., Mahoney, E. B., Lipchik, E. O., and DeWeese, J. A. (1974). Echocardiographic recognition of the congenital bicuspid aortic valve. Circulation, 49, 870-875.

Popp, R. L., Silverman, J. F., French, J. W., Stinson, E. B., and Harrison, D. C. (1974). Echocardiographic findings in discrete subvalvular aortic stenosis. Circulation, 49, 226-231.

Pridie, R. B., Benham, R., and Oakley, C. M. (1971). Echocardiography of the mitral valve in aortic valve disease. British Heart fournal, 33, 296-304.

Radford, D. J., Bloom, K. R., Izukawa, T., Moes, C. A. F., and Rowe, R. D. (1976). Echocardiographic assessment of bicuspid aortic valves: angiographic and pathologic correlates. Circulation, 53, 80-85.

Rodbard, S. (1963). Blood velocity and endocarditis. Circulation, 27, 18-28.

Rothbaum, D. A., Dillon, J. C., Chang, S., and Feigenbaum, H. (1974). Echocardiographic manifestation of right sinus of Valsalva aneurysm. Circulation, 49, 768-771.

Shah, P. M., Gramiak, R., and Kramer, D. H. (1969). Ultrasound localization of left ventricular outflow obstruction in hypertrophic obstructive cardiomyopathy. Circulation, 40, 3-11.

Wray, T. M. (1975a). Echocardiographic manifestations of flail aortic valve leaflets in bacterial endocarditis. Circulation, 51, 832-835.

Wray, T. M. (1975b). The variable echocardiographic features in aortic valve endocarditis. Circulation, 52, 658-663.

Requests for reprints to Dr. P. A. N. Chandraratna, University of Oklahoma Health Sciences Center, Division of Cardiology, P.O. Box 26901, Oklahoma City, Oklahoma 73190, U.S.A. 